\title{
Sonography of Extraaxial Fluid in Neurologically Normal Infants with Head Circumference Greater Than or Equal to the 95th Percentile for Age
}

\author{
David P. Fessell, MD, Daniel A. Frankel, MD, Wayne P. Wolfson, MD
}

The goal of this study was to examine sonographically the extraaxial space in neurologically normal infants with occipital frontal circumference greater than or equal to the 95th percentile for age and correlate these dimensions with neurologic follow-up findings to determine a range of normal values. We thus hope to obviate unnecessary workup of these patients, including additional imaging or intervention. Our results demonstrate that for infants with a craniocortical width or sinocortical width less than $10 \mathrm{~mm}$, the negative predictive value and specificity for developing a neurologic abnormality during the 55 week follow-up period were 94 to $100 \%$. Thus, for neurologically normal infants with occipital frontal circumference greater than or equal to the 95th percentile for age and a head ultrasonogram that is otherwise normal, a craniocortical or sinocortical width of up to $10 \mathrm{~mm}$ can be considered within normal limits. Clinical follow-up evaluation is prudent, but additional imaging of these infants is not required. KEY WORDS: Macrocrania; Extraaxial fluid; Occipital circumference.
T he CCW and SCW are the standard sonographic parameters for evaluating the extraaxial space. As defined by Libicher and

\section{ABBREVIATIONS}

CCW, Craniocortical width; SCW, Sinocortical width; OFC, Occipital frontal circumference; ACTH, Adrenocorticotropic hormone; CT, Computed tomography; MR, Magnetic resonance

Received December 9, 1999, from the Department of Radiology, University of Michigan Medical Center (D.P.F.), Ann Arbor, Michigan; the Department of Radiology, Palos Community Hospital (D.A.F.), Palos Heights, Illinois; and the Department of Radiology, Henry Ford Hospital (W.P.W.), Detroit, Michigan. Revised manuscript accepted for publication April 4, 2000.

Address correspondence and reprint requests to D.P. Fessell, MD, Department of Radiology, University of Michigan Medical Center, Taubman Center (TC) 2910G, 1500 East Medical Center Drive, Ann Arbor, MI 48109-0326.
Troger in a normal population, these parameters have upper limits of normal of $4 \mathrm{~mm}$ and $3 \mathrm{~mm}$, respectively. ${ }^{1}$ We have observed that neurologically normal infants with an OFC of $95 \%$ or greater frequently have extraaxial fluid collections exceeding these limits (Figs. 1, 2). These infants, referred for screening ultrasonography to exclude hydrocephalus or other causes of macrocrania, frequently have no other abnormalities.

It would certainly be desirable to avoid unnecessary evaluation with additional imaging, usually including sedation and considerable expense, if these fluid collections are benign. However, the differential diagnosis for extraaxial fluid collections includes many pathologic and potentially devastating conditions. These include subdural or subarachnoid hemorrhage, subdural hygroma, infection, atrophy, genetic syndromes, prematurity, and external hydrocephalus. Enlarged subarachnoid spaces have also been known to occur secondary to admin- 


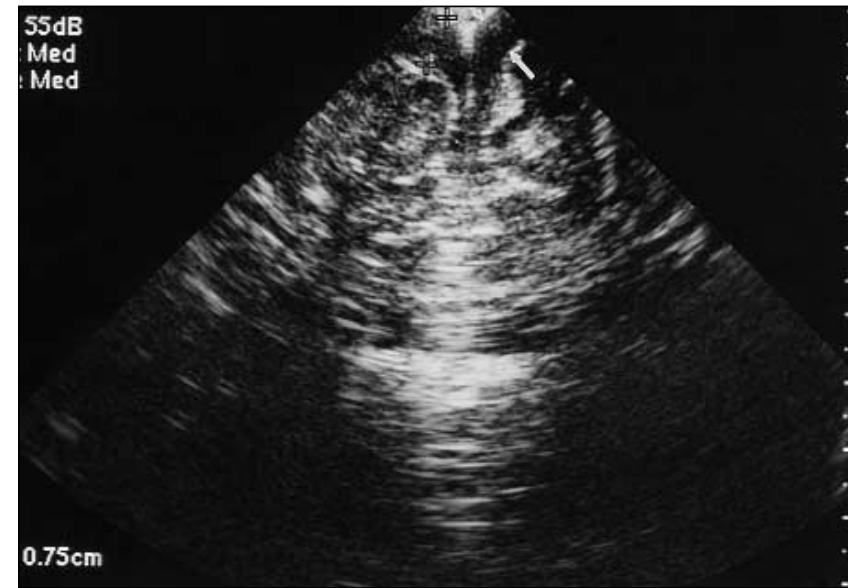

Figure 1 Coronal ultrasonogram of extraaxial fluid. The SCW measured $7.5 \mathrm{~mm}$ (between markers) (right side). On the left side, arrows demonstrate how the SCW was measured (i.e., as the shortest distance from the lateral wall of the superior sagittal sinus to the adjacent surface of the cerebral cortex).

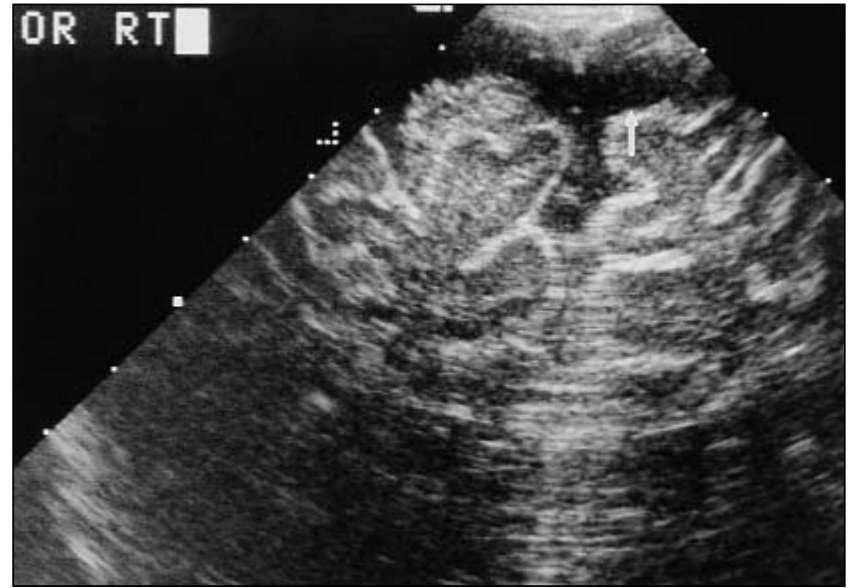

Figure 2 Coronal ultrasonogram of extraaxial fluid. The CCW, measured as the shortest distance from the calvarium to the cerebral cortex (arrows), was $10 \mathrm{~mm}$. Measurements were made on the side with the largest fluid collection.

macrocrania, enlarged head size). In order to study an otherwise normal population, patients were excluded if the history reported a neurologic abnormality or if any additional sonographic abnormalities were present. Using these criteria, 90 potential cases of OFC greater than or equal to the 95th percentile were identified.

Medical records in these 90 potential cases were reviewed to document OFC of $95 \%$ or greater for age prior to the sonographic examination. A standard head circumference chart was used to determine head circumference percentile for age ${ }^{20}$ Chart review also ensured that no neurologic abnormalities were noted prior to the ultrasonogram. Neurologic abnormalities were defined broadly to include any type of developmental delay, including language delays and delays in gross motor development. A total of 32 patients were excluded on the basis of these criteria. In 20 additional cases, clinical or radiologic data were not available, and these patients also were excluded. Thirty-eight patients with 40 sonographic examinations ( 2 patients had follow-up ultrasonographic examinations) thus constitute the study population.

Sonographic examinations were reviewed and the CCW and SCW were measured in a manner similar to the method of Libicher and Troger. ${ }^{1}$ The CCW was measured as the shortest distance from the calvarium to the surface of the cerebral cortex. The SCW was measured as the shortest distance from the lateral wall of the superior sagittal sinus to the surface of the cerebral cortex. The largest extraaxial fluid collection noted in any coronal plane was measured to determine the CCW and SCW (Figs. 1, 2). If the CCW
We retrospectively reviewed 871 consecutive reports of cranial ultrasonographic examinations from January 1991 to January 1997 for any clinical history indicating an enlarged head size (e.g., history of OFC greater than or equal to the 95th percentile, 
measured less than $4 \mathrm{~mm}$ or the SCW less than $3 \mathrm{~mm}$, the study was considered to be within the previously described normal range, and further characterization of the findings was not performed. ${ }^{1}$ If the CCW measured more than $4 \mathrm{~mm}$ or the SCW more than $3 \mathrm{~mm}$, exact values were measured with calipers using the scale on the film, or the values were obtained from electronic cursor measurements if present. The medical records in the 38 cases were reviewed to document the length of follow-up evaluation after ultrasonography. Any neurologic abnormality during the follow-up period was noted.

Ultrasonographic examinations were performed using transducers ranging from 4 to $7 \mathrm{MHz}$ (HDI 3000, Advanced Technology Laboratories, Bothell, WA; Acuson, Mountain View, CA; Acoustic Imaging 5200, Dornier Medical Systems, Phoenix, AZ). The institutional review board at our institution approved this study.

\section{RESULTS}

The results are summarized in Tables 1 to 3 . Descriptive data are shown in Table 1 . In $47 \%$ of cases, the CCW exceeded the previously reported upper limit of normal, and in 53\% the SCW exceeded this limit (Table 2). CCW and SCW measurements both ranged from 0 to $10 \mathrm{~mm}$. For infants who had increased extraaxial fluid, the mean for CCW and SCW was $7 \mathrm{~mm}$. CCW was positively correlated with SCW by the Spearman correlation $(P=0.0004)$.

The mean clinical follow-up time after ultrasonography was 55 weeks. Using stringent criteria, abnormalities that could possibly be categorized as neurologic were identified in two infants on followup examination. In one infant, a transient head lag was noted at 5 weeks after sonography, which sub-

Table 1: Descriptive Data $(n=38)$

\begin{tabular}{lcc}
\hline & Mean (SD) & Range \\
\hline $\begin{array}{l}\text { Age at ultrasonography } \\
\text { (weeks since birth) }\end{array}$ & $29(19)$ & $3-90$ \\
$\begin{array}{l}\text { Time to examination } \\
\text { after head circumference } \\
\text { measurements (weeks) }\end{array}$ & $2(3)$ & $0-19$ \\
$\begin{array}{l}\text { Number of weeks after } \\
\text { sonography to follow-up } \\
\text { evaluation }\end{array}$ & $55(45)$ & $0-178$ \\
$\begin{array}{l}\text { Age at last follow-up } \\
\text { evaluation (weeks since birth) }\end{array}$ & $83(52)$ & $0-209$ \\
\hline
\end{tabular}

SD, Standard deviation. sequently resolved. This infant has otherwise shown normal neurologic development. The CCW measured $5 \mathrm{~mm}$ and the SCW $10 \mathrm{~mm}$ in this infant. In the second infant, the onset of stuttering was reported at approximately 96 weeks after sonography. The CCW measured less than $4 \mathrm{~mm}$ and the SCW less than $3 \mathrm{~mm}$ in this infant. The remaining 36 patients showed no neurologic abnormality on clinical follow-up study. Mean length of follow-up duration for these 36 cases was 45 weeks. Mean length of follow-up duration until a clinical abnormality was detected in the two positive cases was 54 weeks. Using an exact rank sum test, these follow-up periods do not demonstrate a statistically significant difference $(P=0.92)$.

For infants with a CCW of less than $10 \mathrm{~mm}$, the negative predictive value and specificity for developing a neurologic abnormality during the followup period are $94 \%$ and $97 \%$, respectively. For infants with an SCW of less than $10 \mathrm{~mm}$, negative predictive value and specificity are $97 \%$ and $100 \%$, respectively (Table 3). None of the infants in the study underwent surgical or medical treatment of the extraaxial fluid. Neither CT scans nor MR images were obtained for any patient. In two subjects, follow-up ultrasonograms were obtained. In one infant, the amount of fluid increased slightly (CCW from 6 to $8 \mathrm{~mm}$ and SCW from 6 to $9 \mathrm{~mm}$.) In the second infant, CCW and SCW were less than $4 \mathrm{~mm}$ and less than $3 \mathrm{~mm}$, respectively, in both studies. Neither of these infants has demonstrated any neurologic abnormality.

\section{DISCUSSION}

Enlarged CSF spaces, in combination with normal or slightly enlarged ventricles, have been referred to as benign extra-axial collections of infancy, ${ }^{6}$ benign subdural collections of infancy, ${ }^{14}$ external hydrocephalus, 10,18 benign communicating hydrocephalus, benign subdural effusions, ${ }^{9}$ and benign enlargement of the subarachnoid spaces, ${ }^{13}$ indicating diversity in

Table 2: Extraaxial Fluid at Sonography

\begin{tabular}{lcc}
\hline Measurement & $\mathrm{N}(\%)$ & Mean (SD) \\
\hline$C C W(N=40)$ & & - \\
$\leq 4 \mathrm{~mm}$ & $20(53 \%)$ & $7 \mathrm{~mm}(1.6)$ \\
$>4-10 \mathrm{~mm}$ & $18(47 \%)$ & - \\
$S C W(N=40)$ & $18(47 \%)$ & $7 \mathrm{~mm}(1.8)$ \\
$\leq 3 \mathrm{~mm}$ & $20(53 \%)$ & \\
$>3-10 \mathrm{~mm}$ &
\end{tabular}

SD, Standard deviation. 
Table 3: Negative Predictive Value and Specificity for the Development of Future Neurologic Abnormality

\begin{tabular}{lcc}
\hline & $\begin{array}{c}\text { CCW }<10 \mathrm{~mm} \\
(95 \% \mathrm{CI})\end{array}$ & $\begin{array}{c}\mathrm{SCW}<10 \mathrm{~mm} \\
(95 \% \mathrm{CI})\end{array}$ \\
\hline $\begin{array}{l}\text { Negative predictive value } \\
\text { Specificity }\end{array}$ & $\begin{array}{l}94 \%(80-99 \%) \\
97 \%(83-99 \%)\end{array}$ & $\begin{array}{c}97 \%(84-99 \%) \\
100 \%(88-100 \%)\end{array}$ \\
\hline
\end{tabular}

CI, Confidence interval.

theory and the degree of confusion surrounding this topic.

In order to avoid the confounding variable of a coexisting pathologic condition, which complicates earlier studies, we examined a specific and homogeneous patient population, that of clinically and neurologically normal infants with OFC greater than or equal to the 95th percentile for age. It was our goal to determine normal values for the CCW and SCW by correlation with neurologic outcome. If these infants are overwhelmingly normal, further imaging, expense, and concern can be avoided.

Infants with extraaxial fluid measurements of CCW less than $4 \mathrm{~mm}$ and SCW less than $3 \mathrm{~mm}$ were placed in a separate category for data analysis (Table 2). This amount of fluid is within normal limits, and these cases pose no problem to the radiologist. ${ }^{1}$ It is cases with fluid collections above this level that become problematic, and specific measurements of fluid were made for each of these cases.

Increased extraaxial fluid is common in neurologically normal patients with OFC of $95 \%$ or greater and occurred in approximately half of the patients in our study. We have shown that a CCW or SCW of less than $10 \mathrm{~mm}$ predicts the absence of future neurologic abnormality with a negative predictive value and specificity of 94 to $100 \%$. These values are likely closer to $100 \%$, since the two infants in the study who were considered neurologically abnormal on followup examination had only mildly abnormalities, and it is questionable at best if these abnormalities were neurologic in origin. The application of our results is specific to the patient population studied (i.e., neurologically normal infants with OFC greater than or equal to the 95th percentile who otherwise have a normal sonographic examination. Our results cannot be extrapolated to infants who are neurologically abnormal prior to or at the time of ultrasonography or to infants with OFC of less than the 95th percentile for age.

Observed neurologic abnormalities were mild and consisted of one case of stuttering and one case of transient head lag that resolved. Since infants who were neurologically abnormal at the time of sonography were not studied, the values of $10 \mathrm{~mm}$ for CCW and SCW are not by strict definition the upper limits of normal. Values above this level could also be normal. The observed findings do, however, provide reassurance to those who encounter fluid collections in this range and are unsure of their significance.

The average length of clinical follow-up evaluation after ultrasonography was 55 weeks. No statistically significant difference in length of follow-up study was noted for the two patients who developed neurologic abnormalities versus those that remained neurologically normal. However, the power of this calculation is low, given only two neurologically abnormal infants on follow-up examination. The small number of abnormal cases also makes the calculation of sensitivity and positive predictive value (0 to $50 \%$ ) unmeaningful.

The retrospective nature of this study causes several limitations. Detection of neurologic abnormalities was dependent on the detail and rigor of the clinician. This undoubtedly varies from clinician to clinician, but gross neurologic abnormalities and developmental delays should be readily detectable. If possible, prospective sonographic evaluation and routine clinical application should follow the method described by De Vries and coworkers 16 and Frankel and colleagues ${ }^{21}$ using $10 \mathrm{MHz}$ transducers for interrogation of the extraaxial compartment. The advantages of this method include more reliable detection of fluid, more accurate measurement of fluid, and better separation of benign collections from pathologic ones (e.g., a subdural hematoma) that require additional imaging. However, high frequency transducers are not universally available, and not all sonographers are familiar with this technique.

The limitations of ultrasonography for evaluation of extraaxial fluid must be recognized. Successful cranial sonography depends on an open fontanelle and therefore may not be possible in the older infant. Extraaxial fluid collections in the posterior fossa are not readily imaged sonographically and may easily go undetected. The full surface of the anterior and superior convexities is not always well imaged, and small or focal fluid collections in these regions could also go undetected. Fortunately, extraaxial fluid collections in benign macrocephaly are almost always symmetric and involve the cerebral convexities visible through the anterior fontanelle. This feature can be helpful in differentiating these collections from a subdural hematoma or other pathologic conditions. ${ }^{2}$

If the patient has a history of trauma or the examiner has concern for child abuse, CT or MR imaging 
would be more sensitive for the detection of hemorrhage and traumatic injury. MR imaging can be used to distinguish subarachnoid from subdural collections. ${ }^{17}$ However, for the neurologically normal infant with the sole finding of OFC greater than or equal to the 95th percentile for age, ultrasonography remains the recommended screening modality and is the most efficient method of excluding significant pathologic conditions. 5,16 These infants are overwhelmingly normal, and given the anticipated low yield, imaging with CT or MR would not be cost-effective as a screening modality and would involve greater risk owing to radiation and sedation requirements.

In conclusion, in neurologically normal infants with OFC greater than or equal to the 95th percentile for age and a head sonogram that is otherwise normal, a CCW of up to $10 \mathrm{~mm}$ and a SCW of up to 10 $\mathrm{mm}$ have a negative predictive value and specificity of 94 to $100 \%$ for the development of future neurologic abnormality. The results of this study provide confidence for those that encounter fluid collections in this range. Clinical follow-up of these infants is prudent, but additional imaging is not required.

\section{REFERENCES}

1. Libicher M, Troger J: US measurement of the subarachnoid space in infants: Normal values. Radiology 184:749, 1992

2. Barkovitch JA: Pediatric Neuroimaging. Raven Press, New York, 1995, p 463

3. Barlow CF: CSF dynamics in hydrocephalus-with special attention to external hydrocephalus. Brain Dev 6:119, 1984

4. Gordon N: Apparent cerebral atrophy in patients on treatment with steroids. Dev Med Child Neurol 22:502, 1980

5. Babcock D, Han B, Dine M: Sonographic findings in infants with macrocrania. AJR 150:1359, 1988

6. Carolan PL, McLaurin RL, Towbin RB, et al: Benign extraaxial collections of infancy. Pediatr Neurosci 12:140, 1986

7. Ment LR, Duncan CC, Geehr R: Benign enlargement of the subarachnoid spaces in the infant. J Neurosurg 54:504, 1981
8. Kendall B, Holland I: Benign communicating hydrocephalus in children. Neuroradiology 21:93, 1981

9. Mori K, Handa H, Itoh M, et al: Benign subdural effusion in infants. J Comput Assist Tomogr 4:466, 1980

10. Alvarez LA, Maytal J, Shinnars S: Idiopathic external hydrocephalus: Natural history and relationship to benign familial macrocephaly. Pediatrics 77:901, 1986

11. Andersson H, Elfverson J, Svendsen P: External hydrocephalus in infants. Childs Brain 11:398, 1984

12. Pettit RE, Kilroy AW, Allen JH: Macrocephaly with head growth parallel to normal growth pattern. Arch Neurol 37:518, 1980

13. Nickel RE, Gallenstein JS: Developmental prognosis for infants with benign enlargement of the subarachnoid spaces. Dev Med Child Neurol 29:181, 1987

14. Modic MT, Kaufman B, Bonstelle CT, et al: Megalocephaly and hypodense extracerebral fluid collections. Neuroradiology 141:93, 1981

15. Veyrac C, Couture A, Baud C: Pericerebral fluid collections and ultrasound. Pediatr Radiol 20:236, 1990

16. De Vries LS, Smet M, Ceulemans B, et al: The role of high resolution ultrasound and MRI in the investigation of infants with macrocephaly. Neuropediatrics 21:72, 1989

17. Wilms G, Vanderscheuren G, Demaerel PH, et al: CT and MR in infants with pericerebral collections and macrocephaly: Benign enlargement of the subarachnoid spaces versus subdural collections. AJNR 14:855, 1993

18. Maytal J, Alvarez LA, Elkin CM, et al: External hydrocephalus: Radiologic spectrum and differentiation from cerebral atrophy. AJNR 8:271, 1987

19. Briner S, Bodensteiner J: Benign subdural collections of infancy. Pediatrics 67:802, 1980

20. Ross Laboratories Head Circumference Chart, Adapted from Hamill PVV, Drizd TA, Johnson CL, et al: Physical Growth: National Center for Health Statistics Percentiles. Am J Clin Nutr 32:607, 1979. Data from the Fels Longitudinal Study, Wright State University School of Medicine, Yellow Springs, $\mathrm{OH}$

21. Frankel DA, Fessell DP, Wolfson WP: High resolution sonographic determination of the normal dimensions of the newborn intracranial extra-axial compartment. J Ultrasound Med 17:411, 1998 